\title{
Developments in plane parallel flow channel cells
}

\author{
F.C. Walsh*, L.F. Arenas, C. Ponce de León \\ Electrochemical Engineering Laboratory, Energy Technology Research Group, Faculty of \\ Engineering and Physical Sciences, University of Southampton, Highfield, Southampton, \\ SO17 1BJ, United Kingdom \\ * Corresponding author: Frank C. Walsh (f.c.walsh@,soton.ac.uk)
}

\begin{abstract}
Plane parallel electrodes are favoured, in laboratory studies and industry for electrosynthesis, environmental treatment and energy conversion. This electrode geometry offers uniform current distribution while a flow channel ensures a controlled reaction environment. Performance can be enhanced by the use of tailored electrode surfaces, porous, 3-D electrodes, and bipolar electrical connections. Scale-up can be achieved by increasing the electrode size, the number of electrodes in a stack or the number of stacks in a system. Recent trends include a) 3-D printing of fast prototype cell components, b) use of porous 3-D electrode supports and their decoration, c) development of microflow cells for electrosynthesis, d) electro-Fenton treatment of wastewater, and e) computational models to simulate and rationalise reaction environment and performance. Future research needs are highlighted.
\end{abstract}

Keywords: fast prototyping; figures of merit; fluid flow; mass transfer; reaction environment. 


\section{Introduction}

A critical endeavour in electrochemical engineering is the selection of a cell design [1,2], which incorporates appropriate electrode and separator materials, provides a well-defined reaction environment [3] and considers practical needs. The electrochemical reactor incorporates one or more tailored cells and lies at the heart of electrochemical processing at the laboratory, pilotand full industrial scale. Historical perspectives in electrochemical engineering thus remain relevant [4,5], along the discussion of its future possibilities [6]. Two books on electrochemical engineering [7] and its applications [8] have been recently published, along new reviews summarizing the characteristics, development and applications of electrochemical reactors for pilot-scale and industrial processing $[9,10]$.

The plane parallel electrode geometry has remained a favoured choice since the early days of applied electrochemistry due to important benefits:

a) The wide range of electrode materials and forms (2-D and 3-D).

b) The facility to obtain uniform current and potential distributions.

c) The option of having membrane-divided or undivided cells.

d) Scale-up is attainable by increasing electrode surface area or number.

e) Bipolar planar electrodes may have different materials on each side.

g) Fluid flow and mass transport can be controlled in rectangular channels.

This versatility and ease of construction are additional advantages of the parallel plate electrode geometry. Numerous applications can be named, the most relevant being related to production, such as inorganic and organic electrosynthesis, electrowinning, electroplating and electroforming; energy storage and generation, such as fuel cells, redox flow batteries, and metal air batteries; and water treatment, such as electrodialysis, decontamination and 
environmental remediation. Although parallel plate cells have been used in industrial processing for over 140 years, it is only in the last decades that the need for energy efficiency and sustainability in industrial and energy storage operations has become urgent [11]. It is reasonable then, to expect realistic, focused research efforts from the electrochemical community on this matter.

Many laboratory studies start in an agitated beaker while a stirred tank is common in pilotscale studies; such convenient arrangements offer an undefined, irreproducible and difficult to scale reaction environment. In contrast, the incorporation of plane parallel electrodes in a flow channel offers well-defined hydrodynamics and rates of mass transfer to/from electrodes together with ease of reactant supply and gas removal. The important features and reaction environment in an established cell of $64 \mathrm{~cm}^{2}$ projected electrode area as an example of a laboratory flow electrolyser have been considered in two complementary reviews $[12,13]$.

This review highlights the features and benefits of parallel plate cells and their established uses in order to encourage R \& D. Recent trends and future needs in rectangular channel flow cells are highlighted. These include: a) 3-D printing of fast prototype cell components, b) microflow cells for electrosynthesis, c) water treatment vie electro-Fenton and d) computational models to simulate and rationalise reaction environment and performance.

\section{3-D printing of fast prototype cell components}

Traditional approaches to the construction of flow cells tend to use subtractive machining in a centralised workshop, milling and drilling being common processes to shape solid electrodes or electrochemically inert polymer cell components and frames. Fast prototyping, especially 3- 
D printing, along with digital design and imaging software, has transformed cell design and component fabrication $[14,15]$.

3-D printed polymer electrode frames and flow channels have been designed for laboratory redox flow batteries [16], to examine the impact of manifolds and turbulence promoters on hydrodynamic and electrochemical performance [17] and its current distribution in situ [18]. Suitable 3-D printing techniques can be used to produce elastomeric seals, polymeric flow frames and metal electrodes. The printing of porous 3-D electrodes in stainless steel and titanium mesh and foam has started to be explored $[19,20]$. In fact, all components of an electrochemical cell and tailored flow cells could be 3-D printed in a single operation using multimaterial 3-D printer recently developed [21].

A review of flow cell design and performance [10] has highlighted the growing importance of digital software for design, visualising, imaging and revising prototypes, including those using rectangular channels. As illustrated by Fig. 1, following the manufacture of cell components by 3 -D printing, its reaction environment can be modelled numerically, then experimentally validated, followed by an iterative process to increase efficiency and reliability. The final design can then be manufactured using conventional manufacture if suitable. Further advances could be realised in the future. Computer-controlled robotics may be used to assemble the cell, hydraulically and electrically test it and operated. In this fashion, a high degree of automation can be achieved, which can be integrated into the design-image-manufacture-assemblyevaluation procedure.

\section{Electrode surfaces decorated and coated by electrocatalysts}


Productive electrodes can be produced by a suitable combination of structure, surface area and electrocatalytic activity, which can be incorporated by a functional layer applied to the substrate material. Diverse coating and decorating techniques exist, permitting the fabrication of tailored porous electrodes with enhanced properties [22], some of them with hierarchical structures. Electrochemical surface finishing processes, such as anodising, electroplating, electroless deposition, galvanic replacement and electrophoresis can be used to coat and decorate varied substrates [23]. In addition to classical 2D foils and plates, suitable 3-D substrates can be mesh, foam, felt and particulate bed (e.g., in rectangular mesh boxes). The stability and lifetime of the functional coatings is an inevitable consideration and should be studied and in realistic scenarios.

Recent activity in decorated and hierarchical electrode materials comprises:

a) Miscellany of metal, carbon and ceramic substrates, especially 3-D porous materials,

b) Production of diverse nanostructured surfaces, aiming to increase surface area and activity,

c) Continued use of physical coating techniques, such as vapour and plasma deposition, and electrochemical techniques, such as anodising and electrodeposition,

d) Increasing use of hydrothermal methods, electrophoresis and electrospinning to produce hierarchical structures.

The growing adoption of coated porous, 3-D substrates is illustrated by several contributions. For instance, a TiC-doped palladium/nickel foam cathode has been used for electrocatalytic hydrodechlorination of 2,4-DCBA [24]. Various electrodeposited Pt-Ti felt electrodes have been studied for their high volumetric mass transfer coefficient in the Ce compartment of a Zn- 
Ce redox flow battery [25] followed by a detailed consideration Pt deposition on Ti mesh [26]. Hydrothermal methods are relatively popular, such as the deposition of $\mathrm{Pd}-\mathrm{SnO}_{2}$ nanostructures on nickel foam for the reduction of hydrogen peroxide [27]. On the other hand, $\mathrm{CuO}-\mathrm{NiO}$ nanowires for $\mathrm{O}_{2}$ evolution have been recently produced though plasma discharge on $\mathrm{Ni}$ foam [28]. Another example is a $\mathrm{NiSe}_{2}$ catalyst coating on the same substrate by the thermal vapour deposition method [29].

The characterisation of the electrochemically active area of electrode supports and catalyst particle size can utilise many techniques [30]. The electrosorption of a single species on a pure metal, e.g., hydrogen monolayer adsorption on platinum via electrical charge under a cyclic voltammogram peak is extensively used [31] but very limited in practice [32], while ubiquitous BET gas adsorption does not measure the electrochemically active area. Furthermore, many novel catalysts are not susceptible to adsorption studies using classical adsorbates, which could lead to alternative techniques. The active area of supports and activity of electrocatalysts deserves a critical and illustrated review.

\section{The development of microflow cells for electrosynthesis}

Microflow cells have long seen use in electroanalysis monitoring but the last decade has seen their increasing exploration in electrochemical synthesis. Many examples using rectangular and circular planar electrodes have been described and commercial cells have become available [33]. In general, the cells are used to synthesise few grams of product and operate at $<10$ amperes with geometrical area electrodes of $1-15 \mathrm{~cm}^{2}$, the electrode gap varies between 50 to $1000 \mu \mathrm{m}$, and the electrodes are contained in a cell of $0.1-10 \mathrm{~cm}^{3}$ volume. Reported volumetric flow velocities vary from 0.01 to $10 \mathrm{~cm}^{3} \mathrm{~min}^{-1}$ giving an estimated mean linear flow velocity 
around 0.001 to $100 \mathrm{~cm} \mathrm{~s}^{-1}$. The essential mean linear flow velocity is not reported in many publications.

The incentive to develop microflow cells include the following benefits:

a) low cost and easy manufacturing of cell prototypes,

b) potentially, high yield and conversion in a single pass,

c) small amount of electrolyte,

d) operating under recirculation batch regime,

e) faster test for a variety of materials such as electrodes, membranes, and electrolytes,

f) low power consumption due to the low cell potential given the short inter electrode gap,

g) relatively small size and facility to operate,

The flow channel is typically formed by two parallel metal foil 2-D electrodes, separated by a gasket, usually PTFE or an inert polymer. The surface area and mass transport towards the electrodes can be increased by using 3-D micromesh, foam, or felt electrodes and turbulence promoters. The most recent examples of microflow cells employ serpentine [34], spiral [35], and interdigitated flow fields [36] to achieve enhanced reactant conversion and mass transfer. However, it is still uncommon to find detailed descriptions of flow or current distribution. A number of identical cells $(2<\mathrm{n}<20)$ placed in series with the electrolyte flow (cascade configuration) can be used to increase the overall reactant conversion in a single pass [37]. Although flow-through cells can have lower pressure drop for a given flow rate [38], the majority of microflow cells have a flow-by configuration due to its ease of construction [39]. 
Mathematical descriptions of the cell behaviour can be used to characterise the microflow cells using the general principles of electrochemical engineering already well documented in the literature [33]. Much effort in microflow cells has been directed towards extending electrode length in order to achieve a high conversion in a single pass [40]. However, even at bench scale, batch recirculation affords high conversion over reasonable time. Electrodes of smaller size can then be used and larger volumes of electrolyte can be managed. Indeed, the expressions for the fractional conversion that includes volumetric flow rate, electrode area and mean mass transport coefficient in a plug flow reactor (PFR) for a single pass or in batch recirculation are very useful to describe the cell performance but seldom used $[1,7,8]$.

Miniaturised cells with Reynolds number $<10$ and mean linear flow rates $<0.01 \mathrm{~cm} \mathrm{~s}^{-1}$, can perform conceptual reactions that are difficult to realise in larger cells. The overlapping diffusion layers, facilitates coupled reactions avoids the use of concentrated supporting electrolyte [41]. Also, low Reynolds numbers in the thin channels $(<0.01 \mathrm{~mm})$ allow them to operate the co- laminar flow of different electrolytes without the need of a membrane or a separator [42]. The scale-up outlook for such cells is limited due to their high pressure drop, minor surface area and restrictive volumetric flow rate. Only numerous microflow cells connected in parallel or series could lead to usefulness in applied scenarios.

\section{Advances in flow cells for decontamination and water treatment}

A continued trend in the application of parallel plane electrochemical cells consists in water treatment by the electro-Fenton reaction. Modifications to the classical flow-by electrode configuration have been proposed. For instance, a flow-through microflow electrolyser with 3- 
D electrodes, which incorporates a novel pressurized-jet aeration device [38]. As shown in Fig.

2, the air introduced by the jet into the electrolyte stream increases oxygen concentration, resulting in the generation of hydrogen peroxide at an efficiency of $98.6 \%$. The process was demonstrated by degrading the pollutant clopyralid. Efforts have been directed towards the scale-up of the process [43].

Another approach to electro-Fenton consists in solar-assisted electrochemical reactors. A recent example considers the optimization of $\mathrm{H}_{2} \mathrm{O}_{2}$ production at pilot plant for water treatment [44]. As shown in Fig. 3, UV/visible light applied to a $2 \mathrm{~m}^{2}$ photo-reactor enhances the homogeneous production of radicals and degradation of pollutants in the recirculating electrolyte. The decontamination system included four electrochemical cells, each having boron doped diamond anodes with a projected area of $0.01 \mathrm{~m}^{2}$. Its use was demonstrated by degrading a $75 \mathrm{dm}^{3}$ recirculating batch of a mixture of pesticides. The solar-assisted mode permitted to remove $50 \%$ the organic compounds in $5 \mathrm{~min}$., whereas the electrochemical-only mode required $120 \mathrm{~min}$. for the same conversion. Clearly, attention should be given to the integration of electrochemical operations into more complex, sustainable processes.

\section{Computational models to simulate reaction environment and performance}

Computational modelling is important in predicting and rationalising the performance of electrochemical cells. While many studies have been limited to model reactions conditions in small laboratory cells, it is pleasing to note that the literature is moving towards multiple reaction products, long term operation and more complex reaction environments at a pilot scale. For instance, parallel plate electrodes used for the conversion of ammonia to nitrogen and hydrogen in an alkaline wastewater electrolyte have been mathematically simulated [45]. Relevantly, the 
governing electrode kinetic equations considered seven chemical species and the cell potential. The model showed the importance of intermediate species and reaction steps in optimising reactor behaviour.

Increasing attention is being paid to cell stack design and performance using commercial software packages. As an example, vanadium redox flow battery stacks for energy storage with conventional bipolar electrodes connected in series and parallel fluid connections, have been compared [46]. Numerical 3-D simulations solved by commercial software incorporated the electrochemical, mass transport, electrical parameters, while an equivalent circuit described the shunt currents among the consecutive cells. Further, the pressure drop over the porous felt electrodes was simulated by computer fluid dynamics The model concluded that a stack array hydraulically connected in parallel resulted in a $10 \%$ higher round-trip efficiency.

Other models are concerned with the current distribution in parallel-plate reactors. For instance, the practical case of a tertiary distribution in a reactor with a perpendicular and cumulative laminar flow at the inlet coupled with a convergent flow along the axial length [47]. The model was based on the numerical solution of the Navier-Stokes equation for the redox species concentration and fluid flow. In combination with limiting current experiments with a model reaction, it is concluded that such geometry tends to homogenise the tertiary current distribution.

Recently, the simulation of electrolyte fluid flow in parallel plane, pre-pilot flow reactor having a mesh-like polymer turbulence promoter in the flow channel has been accomplished by solving the Reynolds-averaged Navier-Stokes (RANS) equations with the $\kappa-\varepsilon$ turbulence model in a numerical 'multiphysics' solver suite [48]. As shown in Fig. 4, the simulation was 
validated by residence time distribution measurements and, relevantly, by the visualization of a tracer dye. This work is a first step towards the optimization of the size, geometry and orientation of inert turbulence promoters in electrochemical flow cells, while the same approach can be implemented to the fluid flow of electrolyte through 3-D porous electrodes, such as mesh. Future advances could be envisaged by simulating two-phase flow.

\section{Summary}

1. The availability of diverse materials in many structural forms, a uniform current distribution and the controlled reaction environment in a rectangular flow channel have contributed to plane parallel cells being the workhorse of electrochemical processing.

2. Versatility can be extended by a) 3-D printing of fast prototype cell components, b) tailored, e.g., nanostructured electrocatalyst decorated and coated electrode surfaces, c) thin gap, microflow cells and d) computational models accessible by desktop and portable computers.

3. Performance enhancement by electrolyte and air jetting, use of GDEs and static polymer net turbulence promoters has been modelled from a fluid flow, current distribution and mass transport perspective.

4. Classical application areas have included hydrodynamic electrochemical sensors and monitoring.

5. Fast developing needs include RFBs, PEMFCs, SOFCs, microflow cell synthesis, and combinatorial screening of catalysts.

6. For mass transport-controlled reaction conditions, the factor $k_{m} A_{e}$ has been obtained as a function of $v$, to aid a cost-benefit analysis of performance. 
7. Increasing attention is being paid to cell stack design and performance, including shunt currents in bipolar electrode cells, using commercial software packages.

8. Recent literature shows a move towards more complex electrode structures and durable electrocatalysts, multiphase electrolytes, real process electrolytes and industrially important reactions.

\section{Future research needs}

1. Adequate data on electrodes and cell design should be documented to facilitate scale-up of electrochemical processes.

2. A controlled and documented reaction environment needs addressing, with due consideration for flow regime, mixing, and current-, potential-, concentration distributions.

3. Accessible computational models need to evolve as an integrated suite tailored to process simulation and scale-up.

4. Electrode characteristics such as the volumetric are of 3-D electrodes, their activity and longevity during cycling should be quantified; Electrocatalytic coatings usually require data on particle size, porosity and durability.

5. Important parameters characterising electrodes in flow channels include the equivalent hydraulic diameter, $d_{e}$, the mean linear flow velocity of electrolyte past the electrode surface, i.e. the superficial velocity, $v$ (hence the channel Reynolds number), the averaged mass transfer as a function of $v$ and the pressure drop over the channel.

6. Literature should reflect energy, cost and environmental aspects, including expression of cell potential components and energy (consumption or production) efficiencies. 
7. Fast prototyping constructional techniques to realise electrodes and cell components, such as 3-D printing, are developing fast. It is important to tailor them towards the needs of electrochemical reactors, including realisation of integrated construction using multi-materials, coating and heat treatment stages; adequate component characterisation, e.g., electrical conductivity, surface roughness and volumetric porosity could be measured as part of routine quality assurance.

8. If microflow cells are to move out of the laboratory to pilot and industrial scale electrosynthesis and processing, optimisation of electrode area, mass transport and due attention to reactant conversion and pressure drop will be needed.

9. The large-scale deployment of microflow cells could be achieved using common electrolyte flow manifolds and convenient electrical connections, the entire assembly might be 3-D printed.

10. A move toward more practical electrodes, electrolytes and reaction conditions will mean greater emphasis on durable coated metal electrodes, environmentally acceptable cell components and electrolytes, multiphase (gas-liquid-solid) and nonaqueous electrolytes.

\section{References and recommended reading}

Papers of particular interest, published within the period of review, have been highlighted as:

- Paper of special interest

•• Paper of outstanding interest.

[1] D. Pletcher, F.C. Walsh, Industrial Electrochemistry, 2nd ed., Chapman and Hall, London, 1990.

[2] H. Wendt, G. Kreysa, Electrochemical Engineering, Springer Science \& Business Media, 1999. 
[3] J. Newman, K.E. Thomas-Alyea, Electrochemical Systems, 3rd ed., John Wiley \& Sons, Hoboken, New Jersey, 2004.

[4] V. Stanković, Electrochemical Engineering - its appearance, evolution and present status. Approaching an anniversary, J. Electrochem. Sci. Eng. (2012) 1-14. doi:10.5599/jese.2012.0011.

[5] S. Bebelis, K. Bouzek, A. Cornell, M.G.S. Ferreira, G.H. Kelsall, F. Lapicque, et al., Highlights during the development of electrochemical engineering, Trans. IChemE. 91 (2013) 1998-2020. doi:10.1016/j.cherd.2013.08.029.

[6] S. Gu, B. Xu, Y. Yan, Electrochemical Energy Engineering: A New Frontier of Chemical Engineering Innovation, Chem. Biomol. Eng. 5 (2014) 429-454. doi:10.1146/annurev-chembioeng-060713-040114.

[7]* T.F. Fuller, J.N. Harb, Electrochemical Engineering, Wiley, New York, 2018.

A recently published book on the applications and theory of electrochemistry. In addition to electrochemical reactors and fuel cells, it covers static batteries, capacitors and electrodeposition.

[8]* K. Scott, Sustainable and Green Electrochemical Science and Technology, John Wiley \& Sons Ltd, 2017.

A recently published book emphasizing electrochemical technologies towards sustainability, such as hydrogen production, electrolysis, $\mathrm{CO}_{2}$ reduction, organic electrosynthesis, energy storage and recycling.

[9] F.C. Walsh, D. Pletcher, Electrochemical engineering and cell design, in: D. Pletcher, Z.-Q. Tian, D. Williams (Eds.), Developments in Electrochemistry: Science Inspired by Martin Fleischmann, John Wiley \& Sons, 2014: pp. 95-111.

[10] F.C. Walsh, C. Ponce de León, Progress in electrochemical flow reactors for laboratory and pilot scale processing, Electrochim. Acta. 280 (2018) 121-148. doi:10.1016/j.electacta.2018.05.027.

[11] B. Obama, The irreversible momentum of clean energy, Science. 355 (2017) 126129. doi:10.1126/science.aam6284.

[12] F.F. Rivera, C. Ponce de León, J.L. Nava, F.C. Walsh, The filter-press FM01-LC laboratory flow reactor and its applications, Electrochim. Acta. 163 (2015) 338-354. doi:10.1016/j.electacta.2015.02.179.

$[13]^{* *}$ F.F. Rivera, C. Ponce de León, F.C. Walsh, J.L. Nava, The reaction environment in a filter-press laboratory reactor: the FM01-LC flow cell, Electrochim. Acta. 161 (2015) 436-452. doi:10.1016/j.electacta.2015.02.161.

A detailed summary of the behavior of a pilot electrochemical flow reactor, comprising electrolyte fluid flow, current distribution, residence time distribution, and numerical simulation. 
[14] H. Lipson, M. Kurman, Fabricated: The New World of 3D Printing, Wiley, Indianapolis, 2013.

[15] J.-Y. Choi, S. Das, N.D. Theodore, I. Kim, C. Honsberg, H.W. Choi, et al., Advances in 2D/3D printing of functional nanomaterials and their applications, ECS J. Solid State Sci. Technol. 4 (2015) P3001-P3009.

[16] L.F. Arenas, F.C. Walsh, C. Ponce de León, 3D-printing of redox flow batteries for energy storage: A rapid prototype laboratory cell, ECS J. Solid State Sci. Technol. 4 (2015) P3080-P3085. doi:10.1149/2.0141504jss.

[17]* C. Ponce de León, W. Hussey, F. Frazao, D. Jones, E. Ruggeri, S. Tzortzatos, et al., The 3D printing of a polymeric electrochemical cell body and its characterisation, Chem. Eng. Trans. 41 (2014) 1-6. doi:10.3303/CET1441001.

Introduces the design and production of electrochemical 3-D printed fast prototypes of parallel plane electrochemical flow cells.

[18] H.A. Figueredo Rodríguez, R.D. McKerracher, C. Ponce de León, F.C. Walsh, Current distribution in a rectangular flow channel manufactured by $3-\mathrm{D}$ printing, AIChE J. 63 (2017) 1144-1151. doi:10.1002/aic.15454.

[19] L.F. Arenas, C. Ponce de León, F.C. Walsh, 3D-printed porous electrodes for advanced electrochemical flow reactors: $\mathrm{A} \mathrm{Ni}$ /stainless steel electrode and its mass transport characteristics, Electrochem. Commun. 77 (2017) 133-137.

[20] J. Lölsberg, O. Starck, S. Stiefel, J. Hereijgers, T. Breugelmans, M. Wessling, 3Dprinted electrodes with improved mass transport properties, ChemElectroChem. (2017). doi:10.1002/celc.201700662.

[21] M. Vaezi, S. Chianrabutra, B. Mellor, S. Yang, Multiple material additive manufacturing - Part 1: a review, Virtual Phys. Prototyp. 8 (2013) 19-50. doi:10.1080/17452759.2013.778175.

[22] F.C. Walsh, L.F. Arenas, C. Ponce de León, Developments in electrode design: structure, decoration and applications of electrodes for electrochemical technology, J. Chem. Technol. Biotechnol. 93 (2018) 3073-3090. doi:10.1002/jctb.5706.

[23] F.C. Walsh, Modern developments in electrodes for electrochemical technology and the role of surface finishing, Trans. Inst. Met. Finish. 97 (2018) 28-42. doi:10.1080/00202967.2019.1551277.

[24] Z. Lou, Y. Li, J. Zhou, K. Yang, Y. Liu, S.A. Baig, et al., TiC doped palladium/nickel foam cathode for electrocatalytic hydrodechlorination of 2,4DCBA: Enhanced electrical conductivity and reactive activity, J. Hazard. Mater. 362 (2019) 148-159. doi:10.1016/j.jhazmat.2018.08.066.

[25] L.F. Arenas, C. Ponce de León, F.C. Walsh, Mass transport and active area of porous $\mathrm{Pt} / \mathrm{Ti}$ electrodes for the $\mathrm{Zn}$-Ce redox flow battery determined from limiting current 
measurements, Electrochim. Acta. 221 (2016) 154-166.

doi:10.1016/j.electacta.2016.10.097.

[26] L.F. Arenas, C. Ponce de León, R.P. Boardman, F.C. Walsh, Electrodeposition of platinum on titanium felt in a rectangular channel flow cell, J. Electrochem. Soc. 164 (2017) D57-D66. doi:10.1149/2.0651702jes.

[27] L. Sun, W. He, S. Li, L. Shi, Y. Zhang, J. Liu, The high performance mushroom-like $\mathrm{Pd} @ \mathrm{SnO} 2 / \mathrm{Ni}$ foam electrode for $\mathrm{H} 2 \mathrm{O} 2$ reduction in alkaline media, J. Power Sources. 395 (2018) 386-394. doi:10.1016/j.jpowsour.2018.05.056.

[28] C. Li, B. Zhang, Y. Li, S. Hao, X. Cao, G. Yang, et al., Self-assembled Cu-Ni bimetal oxide 3D in-plane epitaxial structures for highly efficient oxygen evolution reaction, Applied Catalysis B: Environmental. 244 (2019) 56-62. doi:10.1016/j.apcatb.2018.11.046.

[29] H. Zhou, Y. Wang, R. He, F. Yu, J. Sun, F. Wang, et al., One-step synthesis of selfsupported porous NiSe2/Ni hybrid foam: An efficient 3D electrode for hydrogen evolution reaction, Nano Energy. 20 (2016) 29-36. doi:10.1016/j.nanoen.2015.12.008.

[30] M.J. Watt-Smith, S.P. Rigby, T.R. Ralph, F.C. Walsh, Characterisation of porous carbon electrode materials used in proton exchange membrane fuel cells via gas adsorption, J. Power Sources. 184 (2008) 29-37. doi:10.1016/j.jpowsour.2008.06.015.

[31] M.J. Watt-Smith, J.M. Friedrich, S.P. Rigby, T.R. Ralph, F.C. Walsh, Determination of the electrochemically active surface area of Pt/C PEM fuel cell electrodes using different adsorbates, J. Phys. D: Appl. Phys. 41 (2008) 174004. doi:10.1088/0022$3727 / 41 / 17 / 174004$.

[32] L.F. Arenas, C. Ponce de León, R.P. Boardman, F.C. Walsh, Characterisation of platinum electrodeposits on a titanium micromesh stack in a rectangular channel flow cell, Electrochim. Acta. 247 (2017) 994-1005. doi:10.1016/j.electacta.2017.07.029.

[33]* D. Pletcher, R.A. Green, R.C.D. Brown, Flow electrolysis cells for the synthetic organic chemistry laboratory, Chem. Rev. 118 (2017) 4573-4591.

doi:10.1021/acs.chemrev.7b00360.

A thorough review of the application of electrochemical flow cells to organic electrosynthesis, highlighting the importance of mass transport and plug flow reactor models.

[34] T. Jyothi Latha, S. Jayanti, Ex-situ experimental studies on serpentine flow field design for redox flow battery systems, J. Power Sources. 248 (2014) 140-146. doi:10.1016/j.jpowsour.2013.09.084.

[35] R.A. Green, R.C.D. Brown, D. Pletcher, Electrosynthesis in extended channel length microfluidic electrolysis cells, Journal of Flow Chemistry. 6 (2016) 191-197. doi:10.1556/1846.2016.00028. 
[36] S. Kumar, S. Jayanti, Effect of flow field on the performance of an all-vanadium redox flow battery, J. Power Sources. 307 (2016) 782-787.

doi:10.1016/j.jpowsour.2016.01.048.

[37] S. Sabatino, A. Galia, O. Scialdone, Electrochemical abatement of organic pollutants in continuous-reaction systems through the assembly of microfluidic cells in series, ChemElectroChem. 3 (2015) 83-90. doi:10.1002/celc.201500409.

[38]* J.F. Pérez, J. Llanos, C. Sáez, C. López, P. Cañizares, M.A. Rodrigo, On the design of a jet-aerated microfluidic flow-through reactor for wastewater treatment by electro-Fenton, Sep. Pur. Technol. 208 (2019) 123-129. doi:10.1016/j.seppur.2018.04.021.

Demonstrates the integration of an aeration step into the electrolyte stream of an electroFenton decontamination system, which significantly enhances its efficieny.

[39] C. Gütz, A. Stenglein, S.R. Waldvogel, Highly modular flow cell for electroorganic synthesis, Org. Process Res. Dev. 21 (2017) 771-778. doi:10.1021/acs.oprd.7b00123.

[40] R.A. Green, R.C.D. Brown, D. Pletcher, B. Harji, A microflow electrolysis cell for laboratory synthesis on the multigram scale, Org. Process Res. Dev. 19 (2015) 14241427.

[41] C.A. Paddon, G.J. Pritchard, T. Thiemann, Paired electrosynthesis: micro-flow cell processes with and without added electrolyte, Electrochem. Commun. 4 (2002) 825831.

[42] O.A. Ibrahim, E. Kjeang, Leveraging co-laminar flow cells for non-aqueous electrochemical systems, J. Power Sources. 402 (2018) 7-14. doi:10.1016/j.jpowsour.2018.09.013.

[43] J.F. Pérez, J. Llanos, C. Sáez, C. López, P. Cañizares, M.A. Rodrigo, Towards the scale up of a pressurized-jet microfluidic flow-through reactor for cost-effective electro-generation of $\mathrm{H}_{2} \mathrm{O}_{2}$, J. Clean. Prod. 211 (2019) 1259-1267.

doi:10.1016/j.jclepro.2018.11.225.

[44]* I. Salmerón, K.V. Plakas, I. Sirés, I. Oller, M.I. Maldonado, A.J. Karabelas, et al., Optimization of electrocatalytic $\mathrm{H}_{2} \mathrm{O}_{2}$ production at pilot plant scale for solarassisted water treatment, Applied Catalysis B: Environmental. 242 (2019) 327-336. doi:10.1016/j.apcatb.2018.09.045.

Reports a solar-assisted electro-Fenton pilot plant for water treatment. The addition of a photo-reactor enhances the efficiency of the overall process, which is driven by electrochemical flow reactors.

[45] A. Estejab, D.A. Daramola, G.G. Botte, Mathematical model of a parallel plate ammonia electrolyzer for combined wastewater remediation and hydrogen production, Water Research. 77 (2015) 133-145. doi:10.1016/j.watres.2015.03.013. 
[46] F. Moro, A. Trovò, S. Bortolin, D. Del Col, M. Guarnieri, An alternative low-loss stack topology for vanadium redox flow battery: Comparative assessment, J. Power Sources. 340 (2017) 229-241. doi:10.1016/j.jpowsour.2016.11.042.

[47] A.N. Colli, J.M. Bisang, Combination of cumulative and convergent flows as a means to improve the uniformity of tertiary current distribution in parallel-plate electrochemical reactors, J. Electrochem. Soc. 164 (2017) E42-E47. doi:10.1149/2.0521704jes.

[48]** L. Castañeda, R. Antaño, F.F. Rivera, J.L. Nava, Computational fluid dynamic simulations of single-phase flow in a spacer-filled channel of a filter-press electrolyzer, Int. J. Electrochem. Sci. 12 (2017) 7351-7364. doi:10.20964/2017.08.09.

Demonstrates the simulation and validation of electrolyte fluid flow in parallel plane electrochemical cells having polymer turbulence promoters. 


\section{Figures}

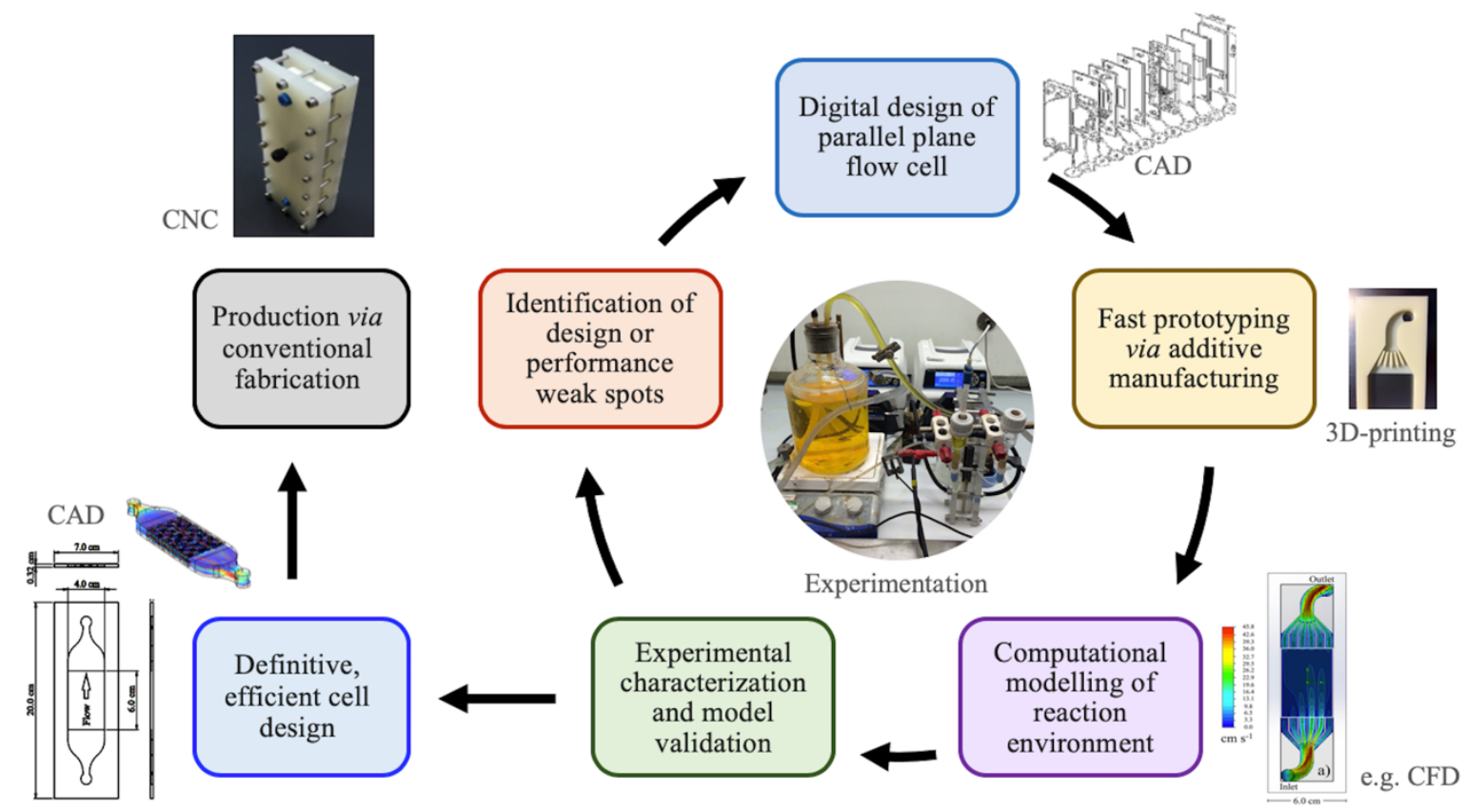

Fig. 1. Modern design process for parallel plane electrochemical flow cells. After the digital design of the cell, a fast-prototype is made using additive manufacturing, permitting the experimental characterization of the reaction environment. The obtained data allows, in turn, to validate numerical models and or identify design flaws, as well as the optimization of the reaction rate. After the iterative process, a final production design can be manufactured using techniques suitable for mass production. Computer assisted drawing (CAD), computer numerical control machining (CNC), computational fluid dynamics (CFD). 
Fig. 2. Concept and experimental arrangement for a jet-aerated flow-through electrochemical cell for the degradation of Clopyralid via electro-Fenton. Reprinted from Pérez et al. [38], On the design of a jet-aerated microfluidic flow-through reactor for wastewater treatment by electro-Fenton, Separation and Purification Technology 208:123-129, Copyright (2019), with permission of Elsevier.

Fig. 3. A pilot plant for solar-assisted electro-Fenton degradation of pyrimethanil and methomyl. a) Photograph of the parallel plane electrochemical cell stacks, b) Photograph of the flow photoreactor, c) Components of the water treatment system: 1) photoreactor, 2) valve, 3) feed tank, 4) power supply, 5) electrochemical reactor, 6) flowmeter, 7) air compressor, 8) pump. Reprinted from Salmerón et al. [44], Optimization of electrocatalytic $\mathrm{H}_{2} \mathrm{O}_{2}$ production at pilot plant scale for solar-assisted water treatment, Applied Catalysis B: Environmental 242:327-336, Copyright (2019), with permission of Elsevier. 

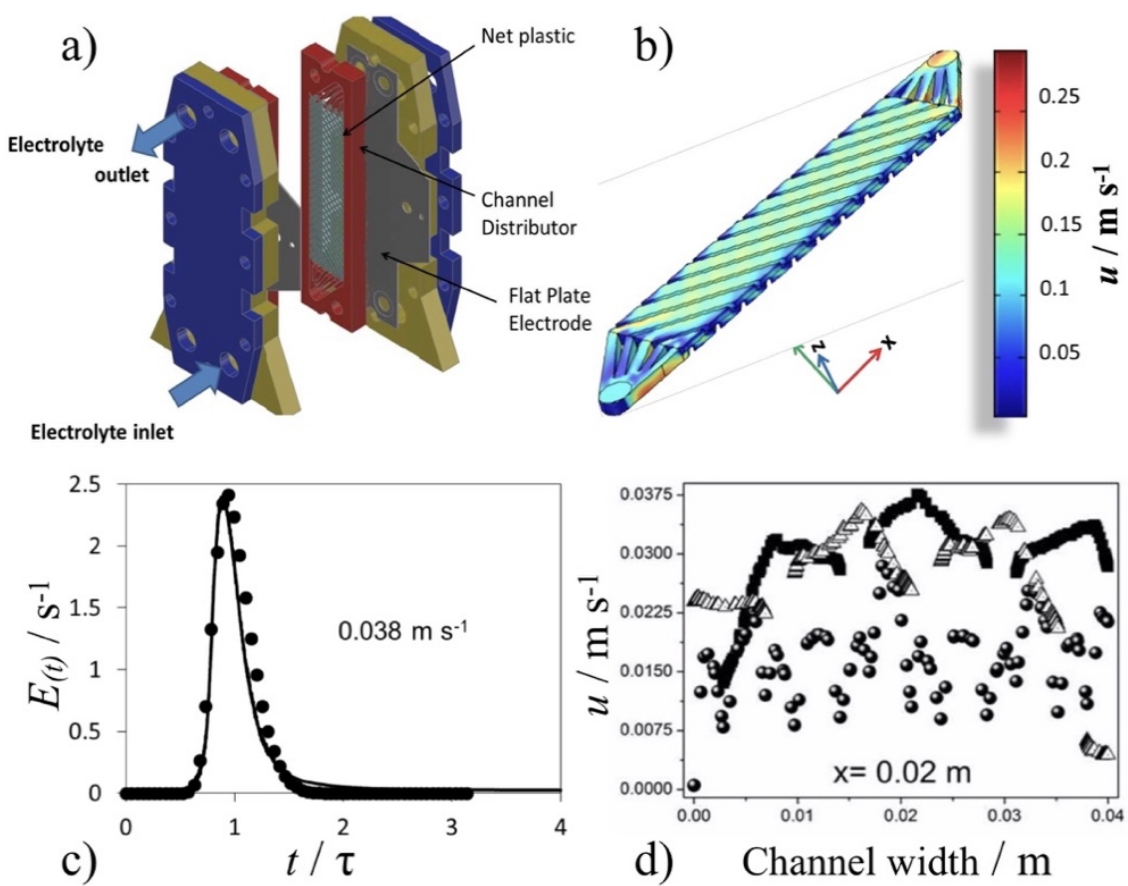

d) Channel width $/ \mathrm{m}$

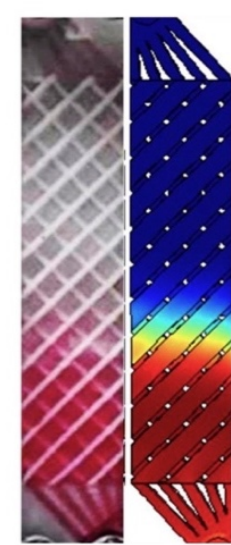

$t=1 \mathrm{~s}$

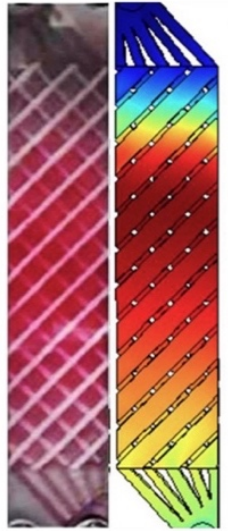

$t=2 \mathrm{~s}$

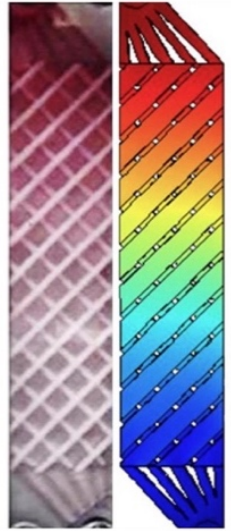

$t=3 \mathrm{~s}$

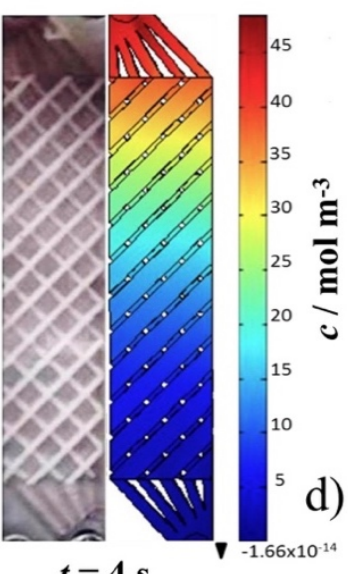

$t=4 \mathrm{~s}$

Fig. 4. A vertically mounted laboratory electrolyser used to validate a computational model during gas-liquid multiphase electrolyte flow in the presence of a polymer mesh turbulence promoter. a) the reactor, b) the simulation domain, showing the polymeric promoter profile and c) streamlines and Re number distribution in a promoter filled rectangular channel at a mean linear electrolyte flow velocity of $11 \mathrm{~cm} \mathrm{~s}^{-1}$. Adapted from Castañeda et al. [48], Computational fluid dynamic simulations of single-phase flow in a spacer-filled channel of a filter-press electrolyser, International Journal of Electrochemical Science 12: 7351-7364, Open access (2017) CC BY 4.0 licence. 